\title{
La contratación administrativa electrónica ${ }^{1}$
}

\section{Electronic administrative engagement}

Recibido: 09 de septiembre de 2014 - Revisado: 29 de junio de 2015 - Aceptado: 28 de agosto de 2015

Juan Pablo Sarmiento E. ${ }^{2}$

Carolina Mariño Manrique ${ }^{3}$

Constanza Forero Tapiero ${ }^{4}$

\section{Resumen}

Este artículo pretende describir la evolución de la contratación administrativa electrónica en Colombia tomando como referencia el desarrollo de una agenda transnacional que procura la implementación de la tecnología y las comunicaciones en la gestión de las compras públicas, buscando determinar sus fortalezas y debilidades actuales. Así, se argumenta que la expansión de las normas de contratación pública electrónica no garantiza que estas sean efectivamente implementadas en las entidades públicas, en la medida en que deficiencias en la gestión de la información pueden impedir el acceso a los datos relevantes de los procesos de contratación pública.

\section{Palabras clave}

Gobierno electrónico, contratación administrativa electrónica, tecnologías de la información y las comunicaciones.

\begin{abstract}
This paper aims to describe the evolution of electronic administrative engagement in Colombia with reference to the development of a transnational agenda that seeks the implementation of technology and communications in the management of public purchases seeking to determine their current strengths and weaknesses. Thus, it is argued that the expansion of the rules of electronic public enhancements does not guarantee that these are effectively implemented in public institutions, to the extent that deficiencies in information management can prevent access to relevant data of pùblic engagement processes.
\end{abstract}

\section{Keywords}

Electronic governance, electronic administrative engagement, information and communication technologies.
${ }^{1}$ Este artículo es resultado de una investigación financiada por la Dirección de Investigación, Desarrollo e Innovación de la Universidad del Norte, Barranquilla, Colombia.

${ }^{2}$ Abogado de la Pontificia Universidad Javeriana, Bogotá, Colombia. Doctor y magíster en Derecho de la Universidad de los Andes, Bogotá, Colombia. Profesor de la Universidad del Norte, Barranquilla, Colombia. Correo electrónico: jpsarmiento@uninorte.edu.co, jua-sarm@uniandes.edu.co

${ }^{3}$ Ingeniera industrial del Politécnico Grancolombiano, Bogotá, Colombia. Máster en Ingeniería Industrial en Universidad del Norte, Barranquilla, Colombia. Profesora de la misma universidad.

Correo electrónico: imarino@uninorte.edu.co

${ }^{4}$ Abogada de la Universidad de La Sabana, Bogotá, Colombia. Cursando maestría en Procesos de Integración Regional de la Universidad de Buenos Aires, Argentina. Este documento forma parte del trabajo realizado en la estancia de investigación en la Universidad del Norte, Barranquilla, Colombia, dentro del programa de maestría en mención.

Correo electrónico:

constanzaft@hotmail.com

Para citar este artículo use: Sarmiento, J., Mariño, C., \& Forero, C. (2015). La contratación administrativa electrónica. Revista Civilizar Ciencias Sociales y Humanas, 15(29), 31-58. 


\section{Introducción}

El desarrollo que han tenido las tecnologías de la información y las comunicaciones (TIC) desde finales del siglo XX ha reformado significativamente la estructura económica, social y política contemporánea, convirtiéndolas en herramientas por medio de las cuales el ciudadano se relaciona con la comunidad y el Estado. Las TIC son una nueva "sociedad red" (Castells, 1996). Impactan $\mathrm{y}$ transforman los factores que determinan el crecimiento económico de los países, centrándolo principalmente en el conocimiento, las ideas y la innovación, desplazando los rendimientos del sector real y de los productos financieros ${ }^{2}$. Por supuesto, lo señalado también depende del nivel de penetración de las TIC en las comunidades, que se puede precisar de acuerdo con los siguientes indicadores: a) Internet, b) telecomunicaciones, c) ordenadores personales y d) comercio electrónico. Estos indicadores serán los que establezcan el uso masivo de los medios electrónicos (Rincón, 2004, p. 434).

El ciudadano que conforma esta nueva sociedad tiene un rol activo en su relación con el Estado, pues el poder que le confiere la información le permite ejercer un control efectivo sobre las actuaciones públicas y participar en la formulación de políticas y lineamientos gubernamentales que antes eran reservados exclusivamente a la administración pública. En este sentido, las TIC plantean nuevos desafíos al ordenamiento jurídico $\mathrm{y}$ al Estado que se basan en los siguientes principios jurídicos de aplicabilidad al entorno electrónico: a) equivalencia funcional de los actos electrónicos, esto es, la equivalencia funcional de los actos jurídicos celebrados a través de medios electrónicos respecto de aquellos actos jurídicos suscritos en forma manuscrita; b) neutralidad tecnológica, que supone que las normas puedan abarcar las tecnologías que propiciaron su reglamentación, así como las tecnologías que se están desarrollando y están por desarrollarse; y c) la conservación del actual régimen del derecho de las obligaciones y contratos privados, pues el comercio electrónico y su aplicabilidad jurídica en todo tipo de transacciones son simplemente un nuevo soporte y medio de transmisión de las voluntades "negociales" o "prenegociales" (Rincón, 2006, p. 34).

El caso español es un ejemplo de este entorno electrónico y del diseño de un sistema garantista de los derechos de los ciudadanos. En esta experiencia europea, la Ley de Administración Electrónica (ley 11 de 2007) resalta las limitaciones establecidas en la Constitución y en el resto del ordenamiento jurídico al e-government, debiendo ajustarse a unos principios mínimos: respetar y asegurar el derecho a la protección de datos de carácter personal; garantizar que en ningún caso el uso de medios electrónicos pueda erosionar el principio de igualdad y la existencia de restricciones o discriminaciones para los ciudadanos que se relacionen con las administraciones públicas por medios no electrónicos; reconocer el principio de accesibilidad a la información y a los servicios por medios electrónicos, es decir, que se utilicen sistemas que permitan obtenerlos de manera segura y comprensible, diseñados para todos los soportes, canales y entornos; establecer sistemas y soluciones tecnológicas interoperables, que posibiliten la cooperación entre todas las administraciones públicas; y que se exija al menos el mismo nivel de garantías y seguridad que se requiere para la utilización de medios no electrónicos en la actividad administrativa; que se respete el principio de proporcionalidad, de modo que solo se exijan las garantías y medidas de seguridad adecuadas a la naturaleza y circunstancias de los distintos trámites y actuaciones; que se asuma el principio de responsabilidad y calidad en la veracidad y autenticidad de las informaciones y servicios ofrecidos a través de medios electrónicos; que se respete el principio de neutralidad tecnológica y de adaptabilidad al progreso de las técnicas y sistemas de comunicaciones electrónicas 
garantizando la independencia en la elección de las alternativas tecnológicas por los ciudadanos y por las administraciones públicas; que la introducción de las nuevas tecnologías ayude a reducir de manera sustancial los tiempos y plazos de los procedimientos administrativos; $y$ que se fortalezca el principio de transparencia y publicidad del procedimiento, por el cual el uso de medios electrónicos debe facilitar la máxima difusión, publicidad y transparencia de las actuaciones administrativas (González, 2009, p. 144).

Las TIC incluyen cambios en el acceso de los ciudadanos a la información estatal y benefician así la evolución de las instituciones jurídico-administrativas, que garantizarían la transparencia, moralidad, economía y celeridad en la prestación de los servicios públicos y el acceso a la información de los ciudadanos, siempre que el país adecúe sus procesos en infraestructuras electrónicas sostenibles (Rincón, 2006, p. 311). Surge así una nueva forma de gobernanza, en la que el gobierno y el ciudadano interactúan en la formulación del devenir público, utilizando las TIC como plataforma de este nuevo escenario: el e-government ${ }^{3}$.

No obstante, para hablar de e-government, es necesario replantear las aproximaciones iniciales, que lo asimilaron a la simple conectividad de la administración. Así, siguiendo a César Calderón (2012), resulta indispensable diferenciar al gobierno electrónico (también llamado administración electrónica) del gobierno abierto. El primero hace referencia a la aplicación de las TIC y sus herramientas, a los procedimientos administrativos preexistentes. Se trata pues, de la simplificación y tecnificación de procesos administrativos, pero no se altera la administración ni se reforma el ejercicio del poder; el gobierno electrónico facilita la vida a los ciudadanos, aunque no transforma la sociedad. Por oposición, afirma el autor citado, "con gobierno abierto se habla fundamentalmente de valores, de repensar administraciones y gobiernos, sus procedimientos y sus dogmas" (p. 27).
De hecho, el gobierno abierto ha conducido a que 144 países se comprometan, como objetivo del milenio, a implementar procesos políticos más igualitarios, que permitan la participación real de todos los ciudadanos utilizando las nuevas tecnologías como un instrumento para promover el desarrollo económico y social de los países ${ }^{4}$. El siglo XXI empezó entonces con la obligación de institucionalizar una realidad socioeconómica, lo que se materializó en primera instancia con la implementación de estrategias y políticas públicas proyectadas consensualmente, entendiendo que la integración regional coadyuvaría a reducir las brechas en infraestructura y desarrollo de las TIC. Esto condujo a la aplicación, también dentro de una agenda regional e internacional, de procedimientos concretos que impactarán la estructura de los Estados.

En efecto, como resultado natural del desarrollo de las TIC y los compromisos internacionales que los Estados adquirieron en torno a la transparencia, gobernanza y rendición de cuentas, la contratación estatal avanza paulatinamente hacia el gobierno abierto. Esto supondría un importante cambio, pues no bastaría con la publicación o acceso a la información, sino que se requeriría, como se expuso en líneas anteriores, de la transformación de la administración y la sociedad.

Por supuesto, América Latina no es indiferente a esta tendencia. En las agendas de todos los gobiernos del subcontinente se ha incluido la tecnificación de los procesos administrativos, considerando por demás, que esta tendencia favorece la transparencia, la eficiencia, la publicidad y la rendición de cuentas. Es por ello que el gobierno electrónico conduce a un proceso de reingeniería de la contratación pública por medios electrónicos. Se trata entonces de la aspiración de modernizar la administración pública en relación con sus adquisiciones, que empieza por generar canales $\mathrm{y}$ formas de comunicación entre el ciudadanoempresario y los gobiernos y sus entidades 
públicas por medios electrónicos, con el objeto de poner a disposición de la comunidad la mayor cantidad de información sobre contratación pública y que, como se presentará más adelante, transita poco a poco hacia etapas más complejas que hacen que las partes del contrato (y la comunidad en general) interactúen por medios remotos de comunicación para finalmente poder, en una fase más avanzada, celebrar la transacción de modo seguro (Laguado \& Suárez, 2007, p. 28).

Así, se tiene que uno de los aspectos centrales del gobierno abierto corresponde a la contratación administrativa electrónica, que requiere, para su eficacia, de normas y de conectividad, tanto de las entidades públicas como de los ciudadanos, que trasciende la simple publicación de la información de las convocatorias y los contratos celebrados en páginas de acceso abierto. La Unión Europea propuso la contratación pública electrónica como un término general utilizado para designar la sustitución de los procedimientos basados en soporte papel por el tratamiento y la comunicación mediante las TIC a lo largo de toda la cadena de contratación pública (González, 2009, p. 142).

Los países de América Latina y el Caribe se obligaron a trazar una ruta conjunta que sirviera de marco a la ejecución de políticas que "promovieran una administración más eficiente, eficaz y transparente a todo nivel" (Declaración de Florianópolis, artículo $\left.5^{\circ}\right)^{5}$. Esto dio paso al planteamiento de estándares comunes que conectan los principales ámbitos de la sociedad con el uso de las $\operatorname{TIC}^{6} \mathrm{y}$, finalmente, a la implantación de un régimen jurídico que sirviera de escenario para el establecimiento y desarrollo del e-government, que involucra los principios y deberes a los cuales deben sujetarse el Estado y el e-ciudadano ${ }^{7}$ en el ejercicio y reconocimiento de sus derechos.

Lo dicho conduciría a la profundización de una democracia activa de doble vía (ciuda-
dano-Estado) que requiere de una regulación de aspectos conexos como el uso de la información en línea, el régimen de registros y datos electrónicos, los mecanismos de control de la gestión pública, la gestión de trámites y procedimientos expeditos, la firma electrónica y otros aspectos que han ido delimitando la formulación del gobierno electrónico ${ }^{8}$.

Esta transformación del Estado también supone compromisos en materia de transparencia. En efecto, la región ya había suscrito, desde 1996, la Convención Interamericana contra la Corrupción (CICC) como instrumento legal que impulsaba la introducción de mecanismos jurídicos para combatirla. En desarrollo de esta convención, se fomentaron cambios sustanciales que sirvieron de engranaje en el proceso de transformación de los gobiernos de la región?. Los principales convenios internacionales sobre corrupción ${ }^{10}$ se sustentan en la necesidad de crear un statu quo que facilite el desarrollo de un buen gobierno que reduzca la corrupción, por lo cual introducen obligaciones atinentes a la adopción de regulaciones relacionadas con el acceso a la información pública, la participación ciudadana y compromisos específicos para los Estados en materia de contratación pública, a los cuales los gobiernos han dado cumplimiento con la implementación de medios electrónicos en los procedimientos internos de contratación, denominado e-GP (electronic government procurement).

El e-GP ${ }^{11}$ supone varias etapas, que pasan de la fase informativa a la operativa, luego a la transaccional (Laguado, 2005) y se extiende a la transformación en línea, para culminar en la fase de democracia en línea. Como se constata, se trata de una ambiciosa agenda, cuya eficacia quiere evaluarse en el presente estudio, pero cuyas ventajas son evidentes: mejora la transparencia del procedimiento $\mathrm{y}$, en consecuencia, se fortalecen los principios de igualdad, imparcialidad y seguridad jurídica; se disminuyen costos para las personas naturales y jurídicas licitadoras y para la 
propia administración pública, se potencia la competitividad interna e internacional del país, se otorga mayor celeridad al procedimiento y se impulsa el mercado único comunitario al emplear instrumentos y técnicas interoperables (González, 2009, p. 140).

Con el marco analítico planteado, se procederá entonces a realizar un estudio descriptivo y crítico del estado actual de la contratación administrativa electrónica, como expresión o resultado de la e-gobernanza. Este examen se hará sobre el diseño institucional desplegado en el país, tomando como referencia experiencias comparadas de la región que han sido modelos influyentes en nuestro diseño y que además, cuentan con las mismas restricciones jurídicas y operacionales, para luego arribar al desarrollo local de la materia y evaluar así, cómo se han implementado dichas normas en el sistema electrónico de compras públicas.

Esto último se evidenciará en el estudio de la plataforma que actualmente opera, que contiene toda la información sobre los contratos administrativos y sistematiza los trámites de las entidades públicas en contratación estatal. De esta manera, se evaluará el sistema a partir de su aplicación, analizando la información suministrada por Colombia Compra Eficiente, que comprende el periodo 2004-2013, y desde allí, se ofrecerán alternativas sobre la gestión de la información que puede sugerir transformaciones en la utilización y divulgación de los datos que son publicados y puestos a disposición de las entidades públicas y los ciudadanos.

Acontinuación se presentarán las prácticas chilena y brasileña como casos donde la implementación del e-GP ha alcanzado niveles operativos y transaccionales importantes, luego se expondrá el caso colombiano, donde se constata un abismo entre las normas relativas a la contratación administrativa electrónica y su efectiva aplicación.

\section{Electronic government procurement en la práctica chilena y brasileña. ¿Por qué lograron mayores resultados?}

Como se explicará enseguida, Colombia siguió de cerca experiencias y diseños institucionales como el canadiense, el chileno y el brasileño. Adoptó inicialmente un sistema como el canadiense, llamado Gobierno en Línea, donde se pretendía establecer un sistema completo e integral, por medio del cual el Estado prestaría sus servicios al público a través de la red, en el marco de lo que se llamó Agenda de conectividad (Rincón, 2006, p. 327) ${ }^{12}$.

No obstante, con el paso de los años y la necesidad de hacer más eficientes y transparentes los procesos de publicación de concursos públicos y mecanismos de selección del contratista, Colombia optó por adoptar herramientas en línea que han sido acogidas en países como Chile y Brasil. En estos casos, se tomaron medidas y se crearon portales de acceso abierto, que liberan y expanden la participación de proponentes en medios electrónicos.

Aunque, como se verá, los modelos de compras públicas electrónicas implementados por Chile y Brasil han alcanzado niveles operativos y transaccionales notables para la región, muy a pesar de las similitudes entre estos países y Colombia en el diseño jurídico del concurso público abierto en medios electrónicos. Quizá, la diferencia radica en que la transformación que se constata en estas experiencias formó parte de un proceso de gran envergadura que modificó la estructura del Estado y en la cual, concurrieron factores determinantes comunes como lo fueron, la lucha contra la corrupción y la participación de la sociedad civil, que pudieron haber resultado mucho más eficaces que la estrategia de Gobierno en Línea y la Agenda de conectividad.

En el caso de Chile, los escándalos de corrupción que en el año 2002 involucraban al Ministerio de Obras Públicas, priorizaron 
la reforma del Estado que ya había iniciado su camino en el año 1997 con el Plan Estratégico de Modernización de la Gestión Pública publicado por el Comité Interministerial de Modernización de la Gestión Pública creado en la presidencia de Eduardo Frei. El plan en comento tuvo como principal logro

[...] poner en marcha el Programa de Reforma del Sistema de Compras y Contrataciones, el cual logra conseguir fondos para lanzar una prueba piloto de una plataforma electrónica; se licita e implementa así la primera versión del software de lo que será ChileCompra (Naser, 2011, p. 27).

Para Santos, el proceso de modernización del sistema de compras públicas chileno estuvo marcado también por factores claves como la influencia de actores sociales como los think tanks; así como por la necesidad de modificar parcialmente el ordenamiento jurídico por los "acuerdos comerciales suscritos con la Unión Europea y el Alca y la participación de las grandes cámaras empresariales" (Santos De, 2011, p. 15).

En la experiencia chilena, la reforma se materializa con la entrada en vigencia en el año 2003 de la Ley de Bases sobre Contratos Administrativos de Suministro y Prestación de Servicios (ley No. 19.886) conocida como Ley Compras Públicas, cuyo principal objeto era el de "uniformar los procesos administrativos de contratación de suministros de bienes muebles y servicios necesarios para el funcionamiento de la administración pública"13. Con el propósito de promover la transparencia y la eficacia en la contratación, se fomentó la institucionalidad mediante la creación de la Dirección de Compras y Contratación Pública (ChileCompra), el Tribunal de Contratación Pública y el Sistema Electrónico de Compras Públicas ${ }^{14}$, por el cual, según lo prescribe esta norma, a todas las entidades públicas cobijadas por la ley, se les impuso la obligación de "cotizar, licitar, contratar, adjudicar y desarrollar todos sus procesos de adquisición de bienes, servicios y obras utilizando únicamente los sistemas electrónicos o digitales que establezca la dirección de compras y Contratación Pública" (Ley 19.886 de 2003).

De acuerdo con lo dispuesto por esta ley, la nueva plataforma electrónica del Sistema de Compras Públicas cuenta con la capacidad para soportar todos los procesos transaccionales de las compras ${ }^{15}$. Como se evidenciará, esta experiencia ha sido seguida de cerca por la práctica colombiana. No obstante, se trata de una plataforma electrónica que no consigue los grados operativos y transaccionales que ha alcanzado Chile. Según Volosin (2010).

[...] al comienzo, con la aplicación del Plan Estratégico 2003-2007, el sistema se orientaba solo al mercado de bienes y servicios a través del portal www.chilecompra.cl. Luego, con el Plan Estratégico 2008-2010, el proyecto se amplió a licitaciones a través de Mercado Público, y al mercado de productos de uso corriente mediante ChileCompra Express, una tienda electrónica que ofrece artículos que incluyen desde suministros de impresoras hasta combustibles y pasajes de avión, previamente licitados mediante convenios marco adjudicados por la DCCP, y ChileCompra Libros, que opera del mismo modo pero cuyo catálogo es específicamente para libros, música, periódicos, etc (p. 11).

El desarrollo de la contratación pública en Chile ha avanzado hacia un modelo interactivo en el cual los datos abiertos se dirigen especialmente al estímulo de la participación de la micro y pequeña empresa, cuyo éxito se refleja en que para el año 2013 hayan recibido en adjudicación el 44,6\% de las contrataciones hechas a través de ChileCompra y la mediana empresa el $13,9 \%{ }^{16}$. Es tal vez esta herramienta la que distancia la práctica colombiana de la chilena (Dirección ChileCompra, 2013).

En Brasil, la primera fase de modernización del sistema de contratación pública se abrió paso, al igual que en Chile, como resultado del impacto que generó en la opinión pública 
los casos de corrupción que en el año de 1993, llevaron al declive del mandato de Fernando Collor de Mello y a la expedición de la Ley de Compras Públicas No. 8.666. Sin embargo, esta reforma fue también el resultado de una política e-government que impulsó el gobierno federal de Brasil, que tuvo como sus primeros proyectos destacables, según Alves y Souza (2011), además de la reforma al sistema de compras públicas, la implementación de la declaración del impuesto de renta por Internet, las urnas electrónicas y Comprasnet ${ }^{17}$.

En consonancia con la mencionada ley, se impulsó la modernización del gobierno federal, por medio del Sistema Electrónico de Compras en Ambientes Virtuales, el Sistema Unificado de Registro de Servicios Generales y el Sistema Integrado de Administración de Servicios Generales (SIASG), implementados estos últimos por la instrucción normativa 5/1995 ${ }^{18}$ del Ministerio de la Administración Federal y Reforma del Estado, con el propósito de ejercer supervisión a los proveedores de la administración pública llevando un registro de los mismos y clasificándolos según criterios de evaluación basados en su capacidad jurídica, financiera y fiscal.

La Ley de Compras Públicas abarcó la contratación de todas las entidades de la administración del gobierno federal, de los Estados, del distrito federal y de los municipios, y estableció en su artículo 22 la subasta (leilão) como una modalidad de contratación pública junto con la competencia, la lista de precios, la invitación, la licitación y el concurso ${ }^{19}$. Sin embargo, no determinó ningún procedimiento a través de medios electrónicos. Fue mediante la ley No. 10.520 de 2002 que se introduce en el ordenamiento jurídico brasileño la posibilidad de utilizar como soporte las TIC, como plataforma en la contratación, al determinar que la subasta inversa o pregão podía realizarse haciendo uso de estos recursos. Para Fernández (2002) "la subasta a la inversa electrónica o pregão eletrônico usando como base el Internet, fue reglamen- tado en diciembre de 2000, con el decreto 3.697 del año 2000", el cual señala el autor, "fue sustituido posteriormente por el decreto No. 5.450 de 2005, que trata el mismo asunto" (Citado por Alves \& Souza, 2011, p. 5).

En este mismo año, el decreto 5.504 estableció como obligatorio para las entidades públicas o privadas que recibieran dinero del gobierno federal, ejecutar por medio del pregão, preferiblemente en su versión electrónica, toda la adquisición de obras, bienes y servicios, lo cual constituyó un detonante en la implementación de este sistema de contratación. Debido a que se trata de un Estado federado, cada Estado (26) y el distrito federal cuentan con un portal de compras públicas, pero es especialmente el portal del distrito federal: www.comprasnet.gov.br ${ }^{20}$ el que ha puesto a Brasil a la vanguardia regional en materia de contratación electrónica. Su éxito consiste en el avance hacia un sistema interactivo en el que cualquier ciudadano puede participar activamente en todo el proceso de contratación pública, o simplemente, tener acceso y fiscalizar las actuaciones contractuales de la gestión pública.

El portal además sirve como plataforma para el ejercicio activo del gobierno abierto, que con los pilares de transparência, credibilidade, prestação de contas e participação ha permitido la implementación de aplicativos creados por la sociedad civil, tales como Reputação S. A. y Reclamações BR, con los que el ciudadano puede respectivamente, por medio del primero, hacer un completo seguimiento a las propuestas formuladas por los concejales de la Cámara Municipal de São Paulo y, mediante el segundo, ejercer un seguimiento estadístico minucioso de las quejas de los consumidores de las principales marcas que se comercializan en el mercado brasileño.

Todo el proceso de contratación se ejecuta en línea, pudiendo el proveedor recibir en su correo electrónico personal las opciones que tiene para participar en procesos de contratación, según su perfil, así como tener acceso 
directo a todas las instancias del mismo. Una vez cerrada la cesión pública de contratación, se genera mediante el portal un informe de cotización electrónica, en el que se detallan todos los eventos de la cesión.

Según estadísticas del Ministerio de Planificación, durante el año 2013 se ejecutaron contrataciones de bienes y servicios por valor de 68,4 billones de reales, en un total de 223,2 mil procesos o contrataciones, aumentando el porcentaje en un 5,8 en relación con el año 2012. El $30 \%$ de este valor total ejecutado en contrataciones públicas se adjudicó a la pequeña y mediana empresa y el $60 \%$ del número de procesos o contrataciones realizadas correspondió a la modalidad por subasta a la inversa electrónica o pregão eletrônico, lo cual refleja la primacía que tiene esta modalidad de contratación administrativa en el ordenamiento jurídico brasileñoy, por demás, aporta elementos de juicio para evaluar las deficiencias prácticas del sistema colombiano de compras públicas.

\section{La experiencia colombiana, ¿rezagada en el estático gobierno electrónico?}

La implementación de los lineamientos del e-government en Colombia se ha desplegado en el marco de la agenda transnacional antes descrita. El gobierno ha buscado alinearse con los estándares de una "gobernanza" que se fundamenta en una nueva manera de formular las políticas públicas y en una administración efectiva y transparente en su gestión. Comienza en 1995 con la estrategia denominada "Gestión pública orientada a resultados" que se consigna en el documento CONPES 2790 de 1995, en el que se propuso el fortalecimiento de la participación ciudadana y el mejoramiento de las capacidades institucionales con la puesta en marcha del Sistema Nacional de Evaluación de Gestión y Resultados, el programa "Trato Hecho" como herramienta de control ciudadano y la aplicación del Sistema de Información Normativa y de Procesos de la Administración Pública-SINPRO, (CONPES 2790 de 1995, p. 13), concebido como un sistema eminentemente informativo sobre los trámites, procesos y normas.

Con esta línea se abrieron paso normas que buscaban el aligeramiento de la gestión pública al permitir a las entidades emplear documentos electrónicos o medios tecnológicos y dirigidas también a facilitar las actividades de los ciudadanos, dándole valor probatorio a los mensajes electrónicos de datos, la supresión de trámites y el reconocimiento de la firma electrónica ${ }^{21}$.

Como se mencionó, la Agenda de conectividad incorporó una política pública más consistente para alcanzar el e-government. No obstante, este sistema contaba con defectos que limitaron su eficacia; así, aunque se implementó el programa Ami Compartel, y se pretendía llegar a localidades remotas en el país, no se ejecutaron programas de capacitación a las comunidades, y la población beneficiaria de este y otros programas, ignoraron las ventajas que tendría el acceso a la información pública y la interacción con las entidades públicas por estos medios. De esta forma, se priorizó el componente electrónico, se dotó a las personas de escasos recursos de medios electrónicos y tecnológicos, pero no se les capacitó sobre el uso de las TIC (Rincón, 2006, p. 347).

Sin embargo, para dar cuenta del verdadero panorama de la contratación pública electrónica en Colombia, dividiremos este título en dos partes, a saber: las compras públicas electrónicas en las normas, donde se hará la descripción más general de las "fases" que se han propuesto en el ordenamiento jurídico colombiano para hacer efectiva las transacciones electrónicas y la rendición de cuentas; en una segunda parte, constataremos el gran abismo que existe entre las normas sobre la materia y su implementación.

\section{Las "fases" de la contratación pú- blica electrónica en las normas}

A partir del año 2000 se inicia una fase normativa que se desarrolla en coordinación con 
la agenda regional sobre e-government, usando como plataforma la Agenda de Conectividad para las Américas. Plan de acción de Quito ${ }^{22}$. Colombia establece como política de Estado la también denominada Agenda de conectividad, la cual tiene como objetivo "masificar el uso de las tecnologías de la información y las comunicaciones -TIC- y con ello aumentar la competitividad del sector productivo, modernizar las instituciones públicas y socializar el acceso a la información" (Organización de los Estados Americanos [OEA], 2002). Para la consecución de este propósito establece como estrategia la implementación del Gobierno en Línea de la Agenda de conectividad ${ }^{23}$ definida como la política por la cual el Estado facilita la gestión en línea de los organismos gubernamentales y apoya su función de servicio al ciudadano, para cuyo propósito se crea el portal www.gobiernoenlinea.gov.co.

La ejecución de la estrategia está contenida en el plan de acción de la circular presidencial 02 de $2000^{24}$, que por primera vez introduce en el ordenamiento jurídico colombiano el concepto de "contratación pública en línea", indicando que esta debe implementarse en la última fase de un cronograma detallado y específico de la estrategia Gobierno en Línea, que debía culminarse en el primer semestre de 2002, usando como base el mencionado portal. Se establece así una estrategia específica que pretendía avanzar del portal meramente informativo con el que ya se contaba.

Por otra parte, la directiva presidencial 12 de 2002 ordena a las entidades de la rama ejecutiva publicar en el portal todos los documentos relacionados con los procesos de selección de contratistas, haciéndose extensiva esta obligación a las contrataciones de todas las entidades públicas incluyendo las del orden territorial por disposición del decreto 2170 de 2002, pero solo cuando las entidades contaran con los medios tecnológicos para hacerlo, lo cual adquirió el carácter de obligatorio por el decreto 2434 del año 2006.
El Consejo Nacional de Política Económica y Social (CONPES) complementó el desarrollo de la contratación pública electrónica mediante los documentos CONPES 3186 de 2002 -que recomendó la creación de un Sistema Electrónico Integral de Contratación Pública en el que instruye que no solo se publique la información de los procesos contractuales, sino se posibilite el desarrollo de los mismos- y CONPES 3248 de 2003 que agrega la implementación de un Sistema Integrado de Contratación Pública que promueva la modernización de la gestión contractual por medio de mecanismos electrónicos, los cuales debieron desarrollarse por el Ministerio de Comunicaciones, según lo instruyó el CONPES 3249 del mismo año, se ordenó la creación del Comité Nacional de Contratación Pública, que aparece posteriormente en el decreto 3620 de 2004.

En el Plan Nacional de Desarrollo (2002, 2006) aprobado por la ley 812 de 2003, se introduce el e-government en la columna vertebral del accionar público, por lo menos en las normas, al establecer el fortalecimiento de la estrategia Gobierno en Línea como parte de un programa nacional de renovación de la administración pública. Esta estrategia conduce a la creación de la Comisión Intersectorial de Políticas y de Gestión de la Administración Pública y se ordena la centralización de la información gubernamental en el portal www.gobiernoenlinea.gov.co a través del decreto 3816 de 2003 y la ley 962 de 2005, respectivamente ${ }^{25}$.

Con base en los anteriores preceptos legales, fue configurándose la base normativa que en Colombia reguló el e-government. $\mathrm{Su}$ desarrollo normativo estructuró y promovió la contratación pública electrónica, como resultado de una iniciativa que puso a las TIC como orientadoras de la gestión gubernamental ${ }^{26}$, y que tuvo sus cimientos en la Cumbre del Milenio, y cuyos preceptos son arraigados como política regional mediante la Agenda de conectividad y otros instrumentos legales ya citados en este documento. 
Se despliega así una fase que comienza en el año 2006 en el marco de una agenda regional que busca afianzar los compromisos de modernizar el Estado mediante el diseño e implementación de estrategias de gobierno electrónico ${ }^{27}$. En este sentido, se expidió la ley 1150 de 2007 por la que se modifica el Estatuto General de Contratación de la Administración Pública introduciendo herramientas que avanzan hacia la fase transaccional de contratación al permitir el uso de instrumentos como la subasta inversa y "otros mecanismos autorizados por el derecho privado, siempre y cuando en desarrollo del proceso de enajenación se garantice la transparencia, la eficiencia y la selección objetiva" (Ley 1150 de 2007, Art. $2^{\circ}$ ), que ordena la centralización de la totalidad de la contratación pública en el Sistema Electrónico de Contratación Pública (Secop), diseñado bajo la dirección del Programa de Renovación de la Administración Pública.

Con el decreto 1151 de 2008 se pretendió culminar la implementación del Gobierno en Línea en el año $2012^{28}$, mediante la consecución progresiva de cinco fases:

1) La fase de información en línea, con plazo de implementación en 2008, en la cual las entidades habilitan sus sitios web para proveer en línea información básica de su gestión; 2) Fase de interacción en línea, con plazo de implementación en 2008 por parte de las entidades del orden nacional y en 2009 por las del territorial, en la cual se habilita la comunicación de dos vías entre entidades, ciudadanos y empresas, con la consulta a bases de datos e interacción con servidores públicos; 3) La fase de transacción en línea, que debe estar finalizada en 2009 por parte de las entidades del orden nacional y en 2010 por las del territorial, en la cual se proveen transacciones electrónicas; 4) La fase de transformación en línea, que debe estar finalizada en el 2010 por parte de las entidades del orden nacional y en el 2011 por las del territorial, donde se realizan cambios en la forma de operar de las entidades para organizar los servicios alrededor de necesidades ciudadanas, con Ventanillas Únicas Virtuales y mediante el uso de la intranet gubernamental y 5) La fase de democracia en línea, que debió estar finalizada en el 2010 por parte de las entidades del orden nacional y en el 2012 por las del territorial, en la cual se incentiva a la ciudadanía a participar de manera activa en la toma de decisiones del Estado y la construcción y evaluación de políticas públicas (art. 5).

Lo anterior, podría resumirse de la manera que presenta la gráfica 1.

Gráfica 1

Fases de implementación del Gobierno en Línea

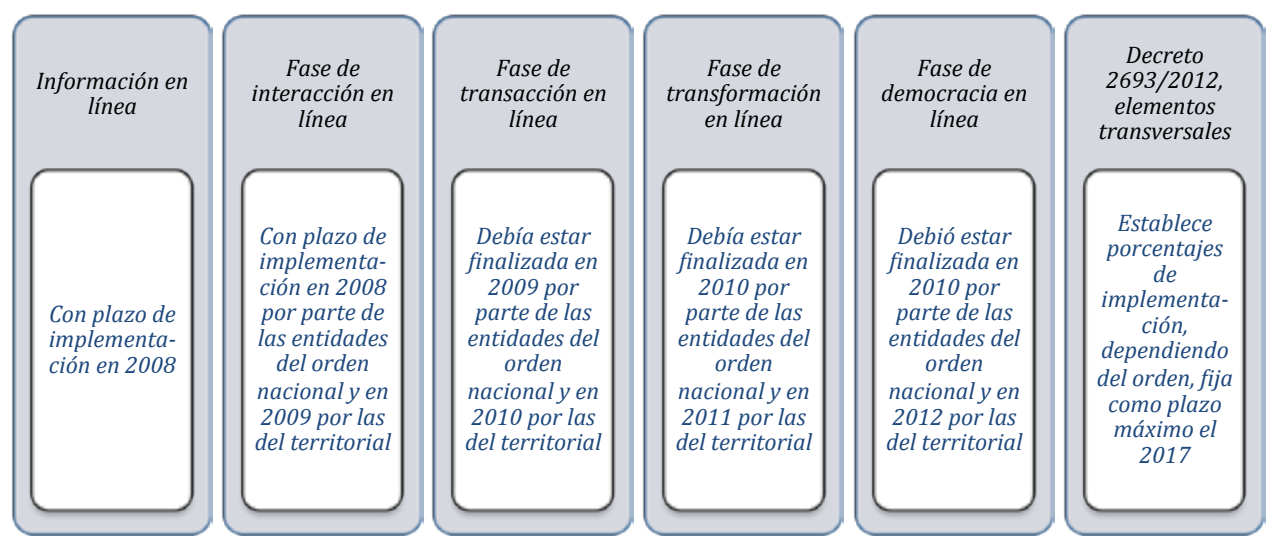

Fuente: elaboración propia con base en el decreto 1151 de 2008. 
Sobre estas fases profundizó el artículo $7^{\circ}$ del decreto 2693 de 2012 del Ministerio de Tecnologías y las Comunicaciones, que al reglamentar la ley 1450 de 2011, indica que la fase de transacción, dentro de la cual se desarrolla la contratación pública, tiene como instrumentos para su avance los "actos administrativos electrónicos, la autenticación electrónica, las firmas electrónicas y digitales, notificación electrónica, pago por medios electrónicos, expedientes electrónicos y archivos electrónicos" (Decreto 2693 de 2012, Art. 7) y añade una sexta fase al desarrollo del e-government.

Esta sexta fase "elementos transversales", introduce un estadio en el que las entidades interactúan activamente entre sí buscando identificar las necesidades del sistema y crear valor agregado que permita mejorarlo permanentemente. Con la creación de la Agencia Nacional de Contratación Pública -Colombia Compra Eficiente- por medio del decreto 4170 de 2011, se profundiza la articulación de e-procurement hacia una etapa transaccional que junto con la implementación de la subasta a la inversa en su modalidad electrónica ${ }^{29}$ prepara las bases para el cumplimiento de las obligaciones contraídas por Colombia en los tratados de libre comercio suscritos en cumplimiento del Plan de Desarrollo (2010-2014) $)^{30}$.

Con todo, aún hoy, las normas más recientes que regulan la materia (decreto 734 de 2012, derogado por el decreto 1510 de 2013) parecen limitadas a la fase de información en línea, y restringen las transacciones, la transformación en línea y las demás fases del Gobierno en Línea, y de igual manera, circunscriben el alcance de los tratados de libre comercio y de integración regional que imponen obligaciones específicas en compras públicas para el país ${ }^{31}$. En realidad, el sistema tradicional parece obsoleto respecto al estado normativo actual, en tanto, se evidencia, las disposiciones más actualizadas se limitan explícitamente a la sistematización y publicación de la información, pero se alejan de forma sustantiva del desarrollo de transacciones y transformación en la forma en que operan las entidades públicas.

En efecto, los tratados de libre comercio suscritos con Estados Unidos, Canadá y México, la Asociación Europea de Libre Comercio (EFTA, por su sigla en inglés) $)^{32}$, la Unión Europea y los países que componen el llamado Triángulo Norte (Guatemala, El Salvador y Honduras), contienen la obligación de disponer de información ${ }^{33}$ relacionada con el proceso de contratación administrativa mediante medios electrónicos, pero incluyen también, en mayor o menor medida, la exigencia de una plataforma que permita ejecutar en ella el proceso de contratación pública en línea, característica propia del sistema de contratación transaccional que debió implementarse en el año 2010, según los presupuestos normativos que ya se indicaron.

Es así como estos acuerdos comerciales promueven la implementación de las TIC en el sistema de compras públicas colombiano, involucrando preceptos que van desde publicar en medios electrónicos la información "normativa" que se vincula con el proceso de contratación (leyes, reglamentos, sentencias y decisiones administrativas) como lo establece el tratado suscrito por Colombia con Estados Unidos, hasta la aplicación completa del proceso de contratación por este medio, como lo regula el acuerdo con la Unión Europea, que comprende determinaciones específicas de contratación mediante la modalidad de subasta electrónica ${ }^{34}$.

En conclusión, las disposiciones contenidas en estos acuerdos constituyen un impulso a la transformación que experimenta el sistema de contratación electrónica de Colombia, pues le imprimen la necesidad de mejorar la fase meramente informativa y hacer una transición efectiva a un sistema transaccional, pero no le graban elementos que permitan el avance hacia una plataforma dinámica dirigida a las necesidades de los ciudadanos como sucede con los modelos regionales desarrollados por Chile y Brasil. 


\section{El abismo entre las normas de con- tratación pública electrónica y su implementación.}

Rincón y Sánchez (2004) opinan que la "esfera externa" del gobierno electrónico es la que presenta mayores avances en Colombia. Sin embargo, para los autores, esta esfera se manifiesta en los siguientes canales de comunicación e interacción: páginas web, portales $-\mathrm{o}$ ventanilla única de servicios públicos-, correo electrónico -no obstante, el tiempo de respuesta, la calidad y la utilidad del mismo infortunadamente aún no son los más apropiados-, listas de distribución -envío de circulares y documentación a ciudadanos que las suscriben-, foros web y foros de noticias, chats, encuestas y estadísticas e intranets.

Con todo, los mismos autores resaltan que las posibilidades reales de suministro de información y transacciones en línea siguen siendo un proceso lento que se ha enfocado en la "interacción unidireccional", es decir, que la vía de atención se da en un solo sentido, y ha omitido procesos de comunicación directos en tiempo real, que darían cuenta de una "interacción bidireccional", que supone una verdadera implementación del $e$ government (p. 9).

Para superar el análisis formalista del complejo normativo que regula la contratación pública electrónica, ejecutamos un estudio de la plataforma que actualmente opera y que contiene toda la información sobre los contratos administrativos y sistematiza los trámites de las entidades públicas en esta materia. Para lograr esto, se solicitó a Colombia Compra Eficiente la información que ha administrado entre los años 2004 y 2013, en la medida en que esta entidad gestiona todos los datos disponibles sobre los contratos administrativos que son enviados por cada entidad contratante ${ }^{35}$. Como respuesta a la solicitud en mención, se obtuvo una base de datos en la que se evidencia una notable debilidad de diseño que imposibilita hacer análisis confiables sobre la actividad contractual de las entidades públicas que reportan información al sistema.

Dicha solicitud se hizo formalmente con un derecho de petición y se respaldó con una visita a las oficinas de Colombia Compra Eficiente, en donde dieron respuesta, señalando, entre otras cosas, debilidades del sistema de información, que se concretan en no contar con un mecanismo que facilite identificar la nación de origen del contratista, lo que representa un riesgo para el país al incumplir las exigencias de publicidad que se estipulan en algunos de los tratados de libre comercio, en las cuales se resalta la obligación de emitir reportes sobre la dinámica de las compras cobijadas en ellos.

El panorama resulta desalentador, en tanto que la base de datos suministrada parece confirmar parte de las afirmaciones de la Contraloría General de la República en informe que publicó en agosto de $2013^{36}$. En dicho informe, la Contraloría señaló

[...] inconvenientes tales como, información fuera de tiempo, contratistas repetidos, cifras mal digitadas, identificación de contratistas errónea, objetos incomprensibles, números de contratos repetidos, modalidad de contratación equivocada y solicitud permanente de prórrogas para el envío de la misma se evidenciaron en todos los ministerios. Esta observación arroja una alerta roja en términos de riesgo, pues es precisamente esta coyuntura el origen para las diferentes vertientes de corrupción (Contraloría General de la República, s.f., p. 23).

Lo anterior demuestra que la formación de la base de datos, la heterogeneidad de fuentes que alimentan las mismas y las inconsistencias de la información que se registra allí hacen imposible efectuar un diagnóstico fiable sobre la concentración de la contratación administrativa en Colombia, el estado de todos los contratos y la identidad del adjudicatario, entre otros elementos mínimos de publicidad. Tanto para esta investigación como para cualquier entidad 
o particular que quisiera realizar veeduría a la contratación estatal en Colombia, resultaría bastante difícil extraer algún resultado confiable sobre la concentración de la contratación pública o cualquier otro diagnóstico.

La base de datos que brindó Colombia Compra Eficiente, muestra inconsistencias en diseño, como ya se mencionó, que de manera importante pero no exclusiva, impactan en la alimentación de la misma. Esta base se nutre de la información obtenida de las diferentes entidades del sector público, esto incluye a cada una de las agencias, alcaldías municipales, instituciones educativas, asociaciones, concejos, centros, Empresa Social del Estado, Empresa de Servicios Públicos, personerías, direcciones y departamentos administrativos del Estado.

De acuerdo con el análisis desplegado en la base de datos, la cantidad de instituciones registradas en el Portal Único de Contratación asciende a 5.955, razón por la que resulta necesario establecer procedimientos sobre el tratamiento de la información de las compras públicas para que sea uniforme y consistente. Lo precedente implicaría no solo una capacitación a todo responsable de transmitir esta información sino también la creación de restricciones de la base de datos que disminuya la ocurrencia de errores del digitador.

Las bases de datos, como la que suministró Colombia Compra Eficiente para este estudio, se definen como "un conjunto de datos organizado de forma adecuada para facilitar la gestión de los mismos" (Carbonell \& Villagrá, 2004). Para ello, la base de datos debe diseñarse, alimentarse y procesarse de manera que responda a las necesidades por las cuales fue creada, que contenga información relevante y que permita ingresar y extraer información segura, robusta y sólida, términos que en grupo conforman lo que comúnmente se conoce como calidad de datos o calidad de la información contenida en la base de datos.
Por lo general, las bases de datos contienen porciones de información que no reflejan la realidad que intentan resumir y en muchas ocasiones incluso alteran esta, presentando inconsistencias, que las más de las veces se incrementan cuando interviene una diversidad de fuentes y agentes en la conformación de la base.

Inclusive, Hernández, Ramírez y Ferri (2004) sostienen que mientras los datos erróneos crecen de manera lineal a medida que aumenta la cantidad de los mismos, las inconsistencias lo hacen de una forma exponencial. Como lo hemos identificado, la base de datos que contiene la información de las compras públicas en Colombia no es la excepción ${ }^{7}$, son muchas las irregularidades que se presentan y el impacto no solo afecta investigaciones académicas como esta, sino que impide una veeduría ciudadana adecuada e interfiere con el seguimiento de procesos administrativos nublando el panorama de transparencia, seguimiento y control que debe acompañar a los procedimientos de contratación del Estado. Es por esto que resulta importante ceñirse a la metodología de bases de datos para garantizar la veracidad y fiabilidad de la información, así como la disponibilidad y accesibilidad a la misma y mitigar las amenazas a las que está expuesta.

Luego de diseñar la base de datos, se debe aplicar un proceso de preparación de la información que contendrá, esto incluye la extracción de diversas fuentes, la limpieza y depuración, la transformación en algunos casos, la consolidación, el cargue y alistamiento para la toma de decisiones y, finalmente, la actualización periódica de los datos (Date, 2001).

El mecanismo de extracción de la información es uno de los más relevantes procesos relacionados con el diseño, desarrollo y aprovechamiento de las bases de datos. Hay diferentes maneras de obtener la información; estas dependen fundamentalmente del medio en el que esta se genere y del tipo de dato que contenga. Cuando la información se halla en 
medios físicos es vulnerable y puede ocasionar problemas para su incorporación en la base y su procesamiento, pero también puede sufrir pérdidas y alteraciones.

Por esta razón, los métodos de extracción de información para bases de datos que involucran el uso de equipos y recursos TIC aportan seguridad y confiabilidad a la información extraída. Si bien en la actualidad el Secop permite consultar los términos y condiciones de las licitaciones y demás ofertas de contratos públicos $\mathrm{y}$, en algunos casos, presentar propuestas por medios electrónicos, mucha de la información relativa al contrato está en físico y debe ser cargada al sistema de manera manual, exponiendo los datos a errores humanos de digitación, lectura e interpretación, e incluso a amenazas propias del manejo en línea de la información, al no disponer de recursos idóneos ${ }^{38}$; esta información debe además tolerar los diversos medios de cargue, muchos de los cuales se componen de diferentes hojas de cálculo y de diferentes programas con distintas actualizaciones y funciones, lo que agrega fragilidad a la información y pérdida de datos ${ }^{39}$.

Siguiendo con lo expuesto por Date (2001), los datos deben limpiarse, esto implica la búsqueda de valores sospechosos o errados y de toda la información faltante. Es en este paso, previo a la alimentación de la base de datos definitiva de la que dispondrá el usuario final, en el que deben realizarse las acciones correctivas, y para el caso puntual de la contratación pública en Colombia, hay una clara ausencia de procesos de este tipo, pues queda expuesta la "contaminación" de la información, la omisión de valores e incluso la presencia de valores errados que permanecen en la base como huellas de pruebas realizadas ${ }^{40}$ que posteriormente no se depuraron y se presentan al usuario que consulta como un dato más.

Date expone también que este proceso de limpieza permite evaluar el paso anterior y poner de relieve inconsistencias e incluso las causas de los errores encontrados, los cuales pueden llegar a ser atribuidos en la mayoría de los casos a la escasa capacitación de quienes capturan la información, la falta de unicidad de criterios al respecto, la ausencia de restricciones y limitaciones para la entrega de la información y el déficit de estandarización y automatización del proceso (Date, 2001; Hernández et al., 2004).

Como se enunció arriba, después de la limpieza de los datos, estos pueden someterse a transformaciones con el objetivo de dar respuesta a asuntos no considerados durante el diseño, lo que representa cierta dificultad de interpretación directamente en la base. Así pues, datos como fechas pueden ser trastocados e incluso los valores que tomen algunas variables cualitativas pueden ser transformados en variables de nivel representadas por números, todo esto con fines de explotación estadística: hallar relaciones entre los datos que no son identificables a simple vista; esto conduce a la aplicación de técnicas estadísticas que resaltan las características de la información obtenida. Sin embargo, en algunos casos, este proceso además de concentrarse en las transformaciones o adaptaciones de la base con fines propios, puede ser útil para identificar errores que fueron pasados por alto.

En este estudio encontramos por ejemplo, que el campo que contiene la fecha de cargue del contrato en el sistema del Secop para algunas celdas comprende además de la fecha, la hora en el mismo campo, esto entorpece el proceso de análisis de una línea de tiempo, $\mathrm{y}$ fue identificado mientras se aplicaba una transformación con el objeto de unificar los formatos de las fechas, proceso que, como se está exponiendo, debió aplicarse antes de cargar la base final de consulta para el usuario.

El proceso de carga de los datos no es menos importante. Sin embargo, si los pasos anteriores se aplicaron correctamente, en este no debería generarse una merma o detrimento en la información. De acuerdo con Date (2001), 
en este paso se realizan tres actividades, a saber: desplazamiento de los datos ya transformados con destino a la base final que será consultada por el usuario, validación y verificación de la integridad de los datos, que de no aplicarse provoca la aparición de datos inválidos o, como son denominados por Cannolly y Begg (2005), "corrompidos" y, finalmente, la construcción de índices necesarios y útiles para las consultas.

La base en análisis presenta falencias evidentes en los dos primeros elementos mencionados, principalmente en el desplazamiento o movilidad de la información hasta la base, al consultar con Colombia Compra Eficiente, no se tiene claridad sobre la ruta que sigue la información, pero a juzgar por los hallazgos de la base de datos obtenida, las entidades envían la información con un destino central en el que se unifica, evidentemente, evadiendo algunos de los más significativos procesos descritos arriba. En razón a la cantidad de usuarios que generan y movilizan la información, en diferentes medios, momentos y usando múltiples recursos para tal propósito, consideramos que el proceso de cargue es una de las debilidades más fuertes de la base y requiere de acciones inmediatas.

Date establece que el último paso para la preparación de los datos en la base es la actualización de los mismos, en razón a que es un proceso cíclico. La base proporcionada por Colombia Compra Eficiente presenta debilidades en este aspecto, sobre todo por la falta de un indicador de actualización relativo a la fecha del último estado atribuido al contrato.

Como se viene exponiendo, los hallazgos de la base de datos reflejan debilidades que conllevan la pérdida de información relevante e incumplimiento de normas sobre la gestión de la misma. La obtención de conclusiones estadísticas se dificulta con la información truncada e incompleta que contiene la base y además, las principales fallas en comento representan un riesgo a la hora de establecer conclusiones respecto de los datos, más aún, cuando el único mecanismo de verificación con el que se cuenta es la revisión individual de los contratos objeto de estudio, que por su elevado número hacen de esta labor incontestable.

Nevado (2010) resalta las principales ventajas de las bases de datos y entre ellas están: la integridad de los datos, la coherencia de los resultados y la mayor seguridad en la información contenida. Estas ventajas se logran con la aplicación correcta de la secuencia ya presentada. Al emplear la base de datos de Colombia Compra Eficiente notamos que dichas ventajas se convierten en desventajas, pues los datos están siendo indiscutiblemente afectados por inconsistencias durante las diferentes fases de manejo de información de la base de datos.

\section{Conclusiones}

En este estudio se tomaron dos aspectos como ejes de análisis. El primero, las transformaciones de la administración pública desde la implementación de las TIC como medio para la gestión administrativa y la gobernanza. Ciertamente, la transformación de la gestión pública trasciende la simple disposición de información y la realización de trámites administrativos por medios electrónicos, para convertirse en una oportunidad para ejecutar cambios de la sociedad, fortalecer la gobernanza y profundizar la democracia. Con estos lineamientos los sistemas electrónicos de compras públicas están llamados a constituirse en una herramienta efectiva para la promoción de la participación ciudadana en la gestión pública y en la construcción de procesos administrativos abiertos, eficientes y transparentes.

Brasil y Chile se destacan por tener prácticas valiosas en la experiencia regional en materia de TIC. Los procesos adelantados por dichos países se originaron en respuesta a escándalos de corrupción que propiciaron la participación de la sociedad exigiendo prácticas transparentes, situación que tuvo como consecuencia, modificaciones legales y adquisición de com- 
promisos internacionales que favorecieron la transformación del Estado. El caso colombiano parecería seguir el mismo camino. No obstante, resulta sorprendente que a pesar de la gran cantidad de normas que se han expedido sobre la materia y los compromisos internacionales adquiridos por el país y pese a las recientes reformas y actualizaciones aplicadas a la plataforma Secop, la ausencia de transaccionalidad en línea prueba el abismo existente entre las disposiciones y la implementación de las mismas.

Ciertamente, una revisión concienzuda y especializada de la información facilitada por Colombia Compra Eficiente permite constatar que, con seguridad, los órganos de control, las veedurías ciudadanas y las mismas entidades públicas originadoras de la información no tienen claridad de los contratos que han adjudicado y celebrado. Resulta preocupante, y lamentablemente funcional para la corrupción y la colonización ilegal del Estado, que la información sobre contratación estatal se encuentre oculta $\mathrm{y}$, peor aún, no pueda ser develada de ninguna manera.

\section{Notas}

1 Una sociedad red, explica Castells (2006), es aquella estructura social compuesta de redes potenciadas por las TIC basadas en la microelectrónica. Es una estructura social en la medida en que los acuerdos organizativos humanos sobre producción, consumo, reproducción, experiencia y poder se expresan mediante una comunicación significativa codificada por la cultura. No obstante, las redes se hacen más eficientes a partir de la base tecnológica actual, en tanto que fortalecieron la flexibilidad -capacidad de las redes para reconfigurarse en función de los cambios del entorno, manteniendo su objetivo-, adaptabilidad -se expanden o reducen con pocas alteraciones- y capacidad de supervivencia -son capaces de funcionar en medio de una amplia gama de configuraciones, resistir ataques a sus nodos y códigos y superar amenazas-.
2 Para Rivera (2003) la "nueva economía se venía denominando desde la década de los ochenta para referenciar el cambio de una economía impulsada por los servicios en lugar de la manufactura. La nueva economía del conocimiento se caracteriza $[. .$.$] porque: 1) Las ideas del consu-$ midor, la información y la tecnología son parte del producto. 2) Es una economía digital. 3) Es molecular, designando la inmaterialización de las corporaciones. 4) Es en red, que constituye una gran masa de relaciones. 5) Hay una creciente eliminación entre la intermediación y el productor. 6) El sector económico preponderante es el resultado de la convergencia entre industrias de la computación y la comunicación" (p. 23).

${ }^{3}$ El e-government, opina Rincón Cárdenas (2006), implica la transformación de la función gubernamental al introducir nuevos valores de comunicación, cooperación y participación interactiva para la toma de decisiones gubernamentales, de tal forma que modifican estrategias de transparencia, desempeño y rendición de cuentas al interior del gobierno.

${ }^{4}$ Declaración del Milenio, aprobada por la Asamblea General de las Naciones Unidas el 19 de septiembre del año 2000. En esta declaración los países miembro tuvieron como referencia para las decisiones relacionadas con la implementación de las TIC, lo instruido en la Declaración Ministerial 2000 del Consejo Económico y Social de las Naciones Unidas (A/55/3 ADV.MIMEO), cuyo documento en su versión definitiva se publicó como: Documentos Oficiales del Consejo Económico y Social, 2000, Suplemento No.1 (E/2000/99).

${ }^{5}$ Esta declaración parecería constituir la primera manifestación política regional de tomar las TIC como eje de desarrollo social y económico. Otras declaraciones regionales que establecieron estrategias definitivas para la implementación del gobierno electrónico en América Latina fueron: Declaración de Itacuruçá (octubre de 2000), Declaración de Río de Janeiro de las TIC para el Desarrollo (junio de 2001), Declaración de 
Bávaro: América Latina y el Caribe (enero de 2003) y Declaración de Principios para el Nuevo Milenio: Construir la Sociedad de la Información: Un Desafío Global para el Nuevo Milenio (Ginebra 2003-Túnez 2005). Paralelamente, la Comisión Europea convoca una reforma estructural de los Estados con el objeto de instaurar una gobernanza basada en la participación de los ciudadanos en la elaboración de políticas públicas mediante el acceso a información actualizada y en línea. Esta gobernanza se fundamenta en los siguientes principios: participación, responsabilidad, eficacia y transparencia. La directriz prevé la implementación de una gobernanza en el ámbito mundial desde estos parámetros. La gobernanza europea, un libro blanco, (Comisión Europea, 2001). Posteriormente la Comisión Europea anunció el lanzamiento de los planes de acción e-Europa 2002, e-Europa 2005, e-Europa 2010. Desde esta línea pero con un énfasis circunscrito al desarrollo de las telecomunicaciones, entendidas estas como un elemento esencial para propagar la integración regional, surgió el Libro azul: políticas de las telecomunicaciones para las Américas, con el propósito primario de promover la privatización y liberalización del mercado de las comunicaciones de manera regional y cuyas últimas versiones se ampliaron para incorporar la implementación de las TIC y los acuerdos de la Organización Mundial del Comercio sobre servicios básicos de telecomunicaciones. Sus compromisos se articulan por los países que forman parte de la Comisión Interamericana de Telecomunicaciones (Citel), es decir, por todos los miembros de la Organización de los Estados Americanos (OEA), por ser un organismo adscrito a esta entidad. Para más información véase: Declaration of Mexico, Inter-American Telecommunication Commission, 11 de marzo de 2010, disponible en: ww.citel.oas.org.

\section{${ }^{6}$ Agenda de conectividad para las Américas y Plan de acción Quito, agosto de 2002.}

${ }^{7}$ Como se explicará más adelante, el programa de Agenda de conectividad no tuvo los resultados deseados en Colombia, precisamen- te, por el factor humano. Aclara Rincón Cárdenas (2006) que "La Agenda de conectividad, como política estatal, copia muchos aspectos del modelo canadiense, pretendía vincular de manera rápida a la comunidad con las nuevas tecnologías de la información y la comunicación. Si se verifican sus objetivos, lo menos que se puede decir de ellos es que eran los más propicios para crear un verdadero escenario de conectividad en Colombia. Sin embargo, el desarrollo de diferentes estrategias que componen esta política olvidaron un componente básico en todo el proceso, el factor humano. Y es que no basta estar acorde con los adelantos tecnológicos, es absolutamente necesario que una comunidad pueda asimilar y comprender las tecnologías, para que pueda utilizarlas" (p. 346).

Lo expuesto, tampoco tuvo en cuenta que el ciudadano debía considerarse como eje central del actuar administrativo. Con todo, la administración no reestructuró al Estado ni rediseñó los procesos de atención al individuo para darle acceso al ciudadano al servicio público. Tampoco garantizó transparencia y acceso a mecanismos de control de los procesos públicos (workflow), ni evitó la dispersión de los servicios electrónicos de las entidades públicas -ubicuidad del portal colombiano- (Rincón \& Sánchez, 2004, p. 11).

${ }^{8}$ El acercamiento mediante iniciativas de carácter regional a materias específicas con tareas concretas en el marco del gobierno electrónico, empieza a mediados de la década del 2000, sobre el particular véanse la Carta Iberoamericana de Gobierno Electrónico aprobada por la XVII Cumbre Iberoamericana de Jefes de Estado y de Gobierno, resolución número 18 de la Declaración de Santiago, noviembre de 2007, Chile; Plan de Acción Regional eLAC 2007 aprobado en la Conferencia Preparatoria Regional Ministerial de América Latina y el Caribe para la Cumbre Mundial sobre la Sociedad de la Información, junio de 2005, Brasil; y Plan de Acción Regional sobre la Sociedad de la Información eLAC 2010, Declaración de La Granja, Foro Ministerial de la Unión Europea 
con América Latina y el Caribe sobre la Sociedad de la Información, marzo de 2010, España.

${ }^{9}$ Se trata de la CICC adoptada y abierta a la firma de los Estados miembro de la OEA, el 29 de marzo de 1996, por la cual se derivaron para los países que la han suscrito obligaciones permanentes como la creación de una autoridad central responsable de ejercer la función de asistencia y cooperación internacional en materia de corrupción, la tipificación penal de delitos relacionados con actos corruptos e implementar mecanismos que alienten a los organismos de la sociedad civil a participar en la gestión pública. Este compromiso es fuente de mutación de los ordenamientos legales domésticos, véanse las evaluaciones y recomendaciones permanentes que ejerce el Mecanismo de Seguimiento de la Implementación de la Convención Interamericana contra la Corrupción de este acuerdo multilateral. A la fecha 32 países han ratificado o se han adherido al convenio. En el año 2011 Colombia designó a los ministerios del Interior y de Justicia, la Fiscalía General de la Nación y la Contraloría General de la República como autoridades centrales para esta convención.

\footnotetext{
${ }^{10}$ Nos referimos en particular al Convenio contra la Corrupción de Agentes Públicos Extranjeros en las Transacciones Comerciales Internacionales de la Organización para la Cooperación y el Desarrollo Económicos que entró en vigor el 15 de febrero de 1999; el Convenio Penal sobre Corrupción del Consejo de Europa, en vigencia desde el 1 de julio de 2002; la Convención contra la Delincuencia Organizada Transnacional de las Naciones Unidas en vigencia desde el 14 de diciembre de 2005; el Convenio Civil sobre la Corrupción del Consejo de Europa, vigente desde el 1 de noviembre de 2003; la Convención contra la Corrupción de las Naciones Unidas, vigente desde el 14 de diciembre de 2005 (de la que se destaca en sus artículos noveno y décimo: "la obligación de establecer sistemas apropiados de contratación pública, basados en la transparencia, la competencia y criterios
}

objetivos de adopción de decisiones y de otorgar información sobre la organización, el funcionamiento y los procesos de adopción de decisiones de su administración pública"); el acuerdo suscrito por los bancos mundiales de desarrollo -Banco Asiático de Desarrollo, Banco Europeo para la Reconstrucción y el Desarrollo, Grupo del Banco Interamericano de Desarrollo y Grupo del Banco Mundial y Convención de la Unión Africana para Prevenir y Combatir la Corrupción-, vigente a partir del $1^{\circ}$ de junio de 2010 , por el cual se estableció entre estas entidades la obligación de inhabilitar con la no participación en contratos de ninguno de los bancos de desarrollo vinculados, a la persona natural o jurídica que incurra en prácticas corruptas. En el año 2010 el Banco Mundial anunció la primera aplicación del acuerdo al sancionar con inhabilidad por un periodo de doce años a la empresa Kwaplah International, Inc. por prácticas corruptas en proyectos financiados por esta entidad, lo cual se hace extensivo a las instituciones financieras que suscribieron el acuerdo; y Open Government Partnership, el propósito de este grupo conformado inicialmente por Brasil, Estados Unidos y México es promover un Estado transparente mediante la participación efectiva de la ciudadanía.

${ }^{11}$ Opinan Font y Ballesteros (2004, p. 73) que desde el punto de vista económico, la adquisición de bienes y servicios por parte de las administraciones públicas ha tenido siempre un tratamiento diferenciado por dos motivos: por su propia importancia en términos de magnitud y por la necesidad de dotar de la máxima transparencia, competencia y, en último extremo, eficiencia a estas compras, ya que si no se efectúan con transparencia, se puede degenerar en favoritismos y clientelismos $y$, por tanto, en corrupción y falta de eficacia en el gasto público.

${ }^{12}$ En la práctica canadiense, el programa de Gobierno en Línea estuvo acompañado de mecanismos que facilitaron su implementación, 
entre otros, SchoolNet, VolNet -Apoyo a la Red del Sector de Voluntarios-, Strategis -página donde el gobierno publicaba información para la búsqueda de nuevos mercados internacionales- y Export Source - portal web donde se publicaba oportunidades de negocios en nuevos mercados, coordinados con agregados comerciales de delegaciones canadienses en otros países- (Rincón, 2006, pp. 327-328).

${ }^{13}$ Contenido de la ley 19.886 de 2003. El reglamento de esta norma entró en vigencia el 24 de octubre de 2004 mediante el decreto supremo 250 , en cuya formulación participó la sociedad civil con más de mil propuestas o planteamientos según indica la misma disposición.

${ }^{14}$ ChileCompra es un sistema de compras y contratación de bienes y servicios asimilable a un mercado electrónico, basado en una plataforma de comercio, donde participan todos los órganos públicos, excepto las entidades estatales que por ley no estén adscritas al sistema. Este sistema obliga a que toda la documentación relativa a un proceso de compra tiene que estar publicada en Internet. El proceso de contratación, en todas sus etapas, se realiza por medios electrónicos utilizando formularios dinámicos que tienen plena validez legal, desde la creación de una solicitud de adquisición hasta la recepción de la factura electrónica y el pago (Barahona, Elizondo, \& Jiménez, 2010).

15 El servicio transaccional alude a la prestación de servicios por medios electrónicos, superando la simple presentación de contenidos en las páginas web (Rincón \& Sánchez, 2004).

${ }^{16} \mathrm{El}$ informe expone que el $91 \%$ de los proveedores que se han adjudicado al menos un negocio con el Estado es mipe (Beláustegui, 2011, p. 46).

17 Para otros autores como Santos De, en este proceso de modernización tuvieron un papel destacado las agremiaciones civiles como el "Sindicato de la Industria de la Construcción Civil del Estado de San Pablo y un grupo de legisladores" (Santos De, 2011, p. 32).

${ }^{18}$ La naturaleza jurídica de la instrucción normativa, es la de establecer en su contenido pautas para el procedimiento por medio del cual se va a ejecutar el mandato de una ley brasileña, en este caso, se refiere a los artículos 34 y 115 de la ley 8.666 de 1993, reglamentados después en su integridad por el decreto 3.722 de 2001 .

19 El precepto legal textualmente indica: "São modalidades de licitação: I - concorrência; II - tomada de preços; III - convite; $I V$ - concurso; $V$ - leilão". (Ley 8.666 de 1993).

${ }^{20} \mathrm{Su}$ precedente es el SIASG, el cual sirvió de soporte para la creación posterior de Comprasnet. En principio tuvo una naturaleza eminentemente informativa, pero en el año 2000 adquiere el carácter transaccional.

${ }^{21}$ Se expiden la ley 527 de 1999 -Ley de Comercio Electrónico-, decreto ley 1250 de 1995 -decreto antitrámites-y ley 489 de 1998. Para Rincón Cárdenas (2003), la ley 527 de 1999 pretendía dotar al país de un instrumento jurídico de impulso a las TIC, y especialmente al comercio electrónico. Sin embargo, esta ley, opina el autor, no es por sí misma una herramienta que integre todos los cuestionamientos que suscitan las nuevas tecnologías.

${ }^{22}$ En efecto, la Agenda de conectividad para las Américas. Plan de acción de Quito de 2002 es el desarrollo de la Declaración del Milenio que se celebró en el año 2000. Este documento define la conectividad como la capacidad interna de una sociedad para comunicarse con su entorno mundial mediante el empleo de las telecomunicaciones, las TIC y los productos de sus industrias de contenidos. Este plan de acción fue presentado por el gobierno ecuatoriano en su calidad de presidente de la Citel, estableciendo tres pasos 
para la implementación de las TIC en la región: evaluación, planificación y valoración de la situación en cada Estado.

${ }^{23}$ Contenido en documento Conpes 3072 de 2000. Establece seis estrategias para la implementación de la Agenda de conectividad, entre las que se encuentra la aquí desarrollada Gobierno en Línea.

${ }^{24}$ El plan de acción se despliega en la directiva presidencial 02 de 2000, fija tres fases a implementar en el portal www.gobiernoenlinea. gov.co: a) información en línea a los ciudadanos para ser terminada el 31 de diciembre de 2000; b) ofrecer servicios y trámites con fecha de terminación el 31 de diciembre de 2001 y c) contratación en línea para ser implantada hasta el 30 de junio de 2002. Dispone también un manual de Políticas y estándares para publicar información del Estado en Internet. Se reglamenta el programa Gobierno en Línea mediante la ley 790 de 2002.

${ }^{25}$ El artículo primero del decreto 3816 de 2003 modificado por el decreto 3043 de 2008 consagró "El objeto de la comisión se concentra en alinear las estrategias y los programas de producción de información, crear mecanismos de control de la gestión pública, mejorar las relaciones con el ciudadano y con sus proveedores y optimizar las inversiones del gobierno evitando las duplicidades en producción".

26 La contratación electrónica $\mathrm{o}$, en su más estricto sentido, la manifestación del consentimiento electrónico a través de medios electrónicos, se observa como una herramienta indispensable en el contexto del intercambio comercial globalizado que depende necesariamente del uso y acceso a las TIC, le concede validez a la contratación electrónica en entornos abiertos y cerrados, bien sea por medio de Internet, intercambio electrónico de datos o por cualquier otro medio electrónico (Rincón, 2004b).
${ }^{27}$ Es este el objeto principal de la Declaración de Santo Domingo celebrada en el año 2006 por los Estados miembro de la OEA, la cual sirvió de fundamento para la posterior expedición en 2007 de la Carta Iberoamericana de Gobierno Electrónico, que funda los derechos y condiciones del gobierno electrónico, acotando la necesidad de simplificar los procedimientos e implementar acciones que brinden seguridad a los datos electrónicos en general. Ya previamente en el año 2005 en la Cumbre Mundial sobre la Sociedad de la Información se había aprobado el Plan Regional de Acción de América Latina y el Caribe denominado eLAC 2007 en el que se habían señalado como metas para el desarrollo del gobierno electrónico el impulso de la contratación electrónica, la firma electrónica, la preservación de la información y medios de pago electrónico, y que dio paso también a la expedición de la ley 1341 de 2009 en la cual se utiliza como principio orientador la sociedad de la información basada en las TIC y la formulación de las políticas públicas que regirán el sector de las TIC en desarrollo de lo cual crea la Agencia Nacional del Espectro. En la Declaración de Lima "por la que se aprueba el plan de acción eLAC 2015 se orientan los compromisos en materia de contratación electrónica involucrando las micro, pequeñas y medianas empresas -mipymes-".

${ }^{28}$ Esta norma cobijó a todas las entidades que conforman la administración pública, en los términos de los artículos $2^{\circ}$ de la ley 962 de 2005 y 39 de la ley 489 de 1998.

${ }^{29}$ Véase decreto 1510 de 2013.

${ }^{30}$ Aprobado mediante la ley 1450 de 2011.

${ }^{31}$ Los decretos reglamentarios de contratación pública, establecen que en el Secop se debe publicar la siguiente información: el aviso de la convocatoria pública; el proyecto de pliego de condiciones y la indicación del lugar físico o electrónico en que se podrán consultar los estudios y documentos previos; las observaciones y 
sugerencias al proyecto a que se refiere el punto anterior y el documento que contenga las apreciaciones de la entidad sobre las observaciones presentadas; la lista corta o la lista multiusos del concurso de méritos; el acto administrativo general que dispone la apertura del proceso de selección; la invitación a ofertar que se formule a los integrantes de la lista corta o multiusos del concurso de méritos; el pliego de condiciones definitivo y la constancia de envío de información a la Cámara de Comercio para la licitación pública; el acta de la audiencia de aclaración de los pliegos de condiciones y en general, las aclaraciones que se presenten durante el proceso de selección y las respuestas a las mismas; el acta de la audiencia de revisión de la asignación de riesgos previsibles; el acto administrativo de suspensión del proceso; el acto de revocatoria del acto administrativo de apertura; las adendas a los pliegos de condiciones; el informe de evaluación; el informe de verificación de los requisitos habilitantes para acceder a la subasta inversa en la selección abreviada de bienes y servicios de características técnicas uniformes y de común utilización; y el acto administrativo de adjudicación del contrato. En los casos de licitación pública, también el acta de la audiencia pública de adjudicación y el acta de declaratoria de desierta de los procesos de selección.

32 El EFTA solo es vinculante entre Colombia con Liechtenstein y Suiza, toda vez que Noruega e Islandia no han realizado el trámite interno correspondiente para incorporar el acuerdo a su ordenamiento jurídico.

33 En general, todos los acuerdos suscritos por Colombia establecen obligaciones propias de un sistema de contratación pública electrónica en su fase informativa (como es la de publicar los avisos de contratación futura por estos medios), para lo que se preparó el portal www.colombiacompra.gov.co; sin embargo, en este sentido debe adaptarse para cumplir con obligaciones complementarias como la de contar con vínculos directos que lleven a todos los avisos electrónicos de contratación futura que van a ejecutar todas las entidades cubiertas, comolo dispone el tratado celebrado con Canadá. Es también característico de estos acuerdos, el deber de cooperación en la implementación de las TIC para el mejoramiento de los sistemas de contratación.

${ }^{34}$ El artículo 186 del acuerdo regula las subastas electrónicas, instaurando obligaciones para las entidades públicas cubiertas: "1) la obligación de informar previamente y a cada participante: el método de evaluación automática, incluyendo la fórmula matemática, que base en los criterios de evaluación establecidos en los pliegos de condiciones y si esta se utilizará en la clasificación o reclasificación automática durante la subasta, así como la obligación de informar los resultados iniciales de la calificación de las ofertas, si el contrato se adjudicará sobre la base de la oferta más ventajosa; [y] 2) el tratamiento que se dará a las ofertas y la adjudicación de los contratos".

${ }^{35}$ El decreto 4170 de 3 de noviembre de 2011 estableció las siguientes funciones de Colombia Compra Eficiente: a) formulación de políticas, planes y programas buscando optimizar la oferta y demanda en el mercado; b) racionalización normativa para una mayor eficiencia de las operaciones; c) desarrollo y difusión de las políticas, normas e instrumentos para facilitar las compras y promover la eficiencia; d) coordinación con otras entidades públicas para el cumplimiento de sus objetivos; e) elaboración de estudios, diagnósticos y estadísticas para mejorar la efectividad del sistema; f) absolución de consultas sobre la aplicación de las normas y expedir circulares sobre la materia; g) apoyo al gobierno en las negociaciones internacionales sobre el tema; h) diseño, organización y celebración de acuerdos marco de precios; i) desarrollo del sistema de compras electrónicas; j) apoyo a los oferentes para facilitar y mejorar su participación; k) difusión de mejores prácticas y coordinación de los programas de capacitación con otras entidades; y 1) apoyo a las entidades territoriales en la gestión de compras. 
${ }^{36}$ El informe en comento expone la concentración de la contratación estatal; esa investigación no se realizó sobre todas las entidades públicas del país, solo se aplicó a ocho ministerios, el Instituto Colombiano de Bienestar Familiar y las corporaciones autónomas regionales, con sus entidades adscritas, vinculadas, gerencias y oficinas que suman un total de 263 sujetos de control. Según el informe citado, sesenta contratistas concentran el $42 \%$ de la contratación de las 263 entidades analizadas. Véase Contraloría General de la República, Informe ejecutivo contratación 2012-2013, metodología y resultados equipo ' $A$ '.

${ }^{37}$ Dentro de las inconsistencias observadas en la base de datos se resaltan las relativas a la falta de información, se presentan muchas celdas vacías en todos los campos, con mayor frecuencia en los que contienen el NIT de la entidad contratante, el nombre o la razón social del contratista, el tipo de documento del contratista, el número de documento o NIT, el número de contrato, la fecha de la firma del contrato, el valor del contrato, los valores de adiciones, el departamento y municipio del contratista, la fecha de inicio de ejecución y el plazo de ejecución. Al hacer las verificaciones sobre las posibles causas de esta ausencia de información se encuentra que la falta de NIT del contratante no se asocia a una entidad particular ni a un tipo de modalidad o estado de contrato, por lo que es evidentemente una falla en el diligenciamiento de la información. Por otra parte, en los demás campos mencionados se liga la carencia de información con el estado del contrato, para los contratos en estado "asignado" no se cuenta con esta información.

Al continuar con el examen de la base de datos, también hallamos que en los campos que contienen valores, como por ejemplo la cuantía, hay diferentes formatos, verbigracia el uso alternativo del signo pesos, la palabra "pesos", las siglas $\mathrm{m} /$ ce y divisas como el dólar USD. Por otra parte, se observan inconsistencias en el uso de puntos y comas, lo cual puede alterar los valores, incrementar o reducir significativa- mente el valor real del contrato, por ejemplo, al escribir "mil" con coma se tiene 1.000 pero si la hoja de cálculo utilizada asigna las comas a los decimales, el valor se reduce a un peso. $\mathrm{Si}$ se emplean dos comas, para escribir un millón (1.000.000) la hoja de cálculo interpreta este valor como un error. En los campos de fechas, como por ejemplo la fecha de creación en el Secop, se presentan pocas inconsistencias y son fáciles de identificar, la falla más evidente es la confusión entre el año y el mes de la creación.

En el nombre o razón social del contratista, así como en el número de documento o NIT la inconsistencia principal es la ausencia de uniformidad de la información, así bien, un mismo proveedor puede estar creado con nombres que son sustancialmente distintos para la base de datos. Por ejemplo, para el proveedor José Humberto López Santos, existen en un mismo año, cuatro nombres que son reconocidos como diferentes por la base de datos, todo esto a causa del uso de las tildes: Jose Humberto Lopez Santos, José Humberto Lopez Santos, José Humberto López Santos, Jose Humberto López Santos.

Se ha encontrado también que en algunos casos este lugar es diligenciado con el mismo nombre del contratante, con datos adicionales como la cédula y texto que no corresponde al nombre o razón social, como por ejemplo: "Ulises Eugenio Martinez Mora, propietario del establecimiento de comercio Servicentro Esso Avda Terc". En el tipo de documento se hallaron irregularidades con la asignación del mismo, lo cual representa una falla grave de la base de datos, pues la única manera de verificar el tipo de documento es accediendo a cada contrato o a la información publicada del contratista. Es así como se tienen cédulas de ciudadanía que aparecen marcadas como NIT de extranjería, NIT o cualquier otra opción distinta de la real. En aquellos años en los que la contratación fue baja, se llevaron a cabo los correctivos pertinentes pero en aquellos con un alto número de contratos, esto no fue posible.

Sobre el número del documento del contratista tampoco hay uniformidad ni unicidad, al 
parecer el campo habilitado para el diligenciamiento de esta celda no tiene las restricciones necesarias, lo que permite que cada encargado lo diligencie según su propio criterio, puntos, comas, barras y otros caracteres que obstaculizan los análisis y que no son fácilmente corregibles. Por último, en el campo asignado para el departamento o municipio del contratista se reportan irregularidades, la principal es la falta de diligenciamiento seguido por la asignación del criterio "otros países" a proveedores que son locales.

${ }^{38}$ Se propone a modo de ejemplo el proceso número SMAMG-LP-001-2014 en el que se dispone de un correo electrónico privado y de un dominio público (yahoo.com), sobre el cual no se puede ejercer vigilancia ni control para la prevención de accesos maliciosos y alteración de la información, lo que pone en riesgo la transparencia del proceso y la veracidad de la información recolectada por ese medio.

${ }^{39}$ De acuerdo con la información disponible en el Secop se pueden publicar documentos relativos al proceso de contratación en los siguientes formatos: PDF, Excel, MP3, AutoCAD, imágenes TIFF, PowerPoint y ASF. Disponibles en: https://www.contratos.gov.co/puc/ preguntasFrecuentes.html

${ }^{40}$ Se evidencia contaminación por pruebas, la base no se limpió antes del envío y se encuentran pruebas desde el año 2009 con una entidad ficticia llamada "zentidadprueba".

\section{Referencias}

Alves, T. R., \& Souza, C. A. (2011). Compras Eletrônicas Governamentais: Uma Avaliação Dos Sites de E-Procurement dos Governos Estaduais. Revista Electronica de Sistemas de Informaçao, 10(1), 1-25.

Aparecido, V., Pineda, C., Romeu, J., \& Juárez, G. (2014). Nuevas perspectivas en la gestión de las administraciones públicas una visión comparada de la contratación pú- blica electrónica. Cuadernos de Gobierno y Administración Pública, 1(2), 159-180.

Araguàs, I. (2012). La regulación de la Administración electrónica y sus principios rectores. Revista Catalana de Dret Públic, 45, 215-237. Recuperado de http:// www.raco.cat/index.php/RCDP/article/ viewFile/260638/347821

Asamblea General de las Naciones Unidas. (2000). Suplemento No. 1 (E/2000/99) (Documentos Oficiales del Consejo Económico y Social). Nueva York: Autor. Recuperado de http://www.unisdr.org/files/ resolutions/N0148752.pdf

Barahona, J. C., Elizondo, A. M., \& Jiménez, G. (2010). Hacia un modelo de compras electrónicas costarricense. San José de Costa Rica: Incae. Recuperado de http:// www.gobiernofacil.go.cr/egob/gobiernodigital/Modernizacioncompraspublicas/ documentoscompraspublcas/hacia_un modelo_de_compras_electronicas_costarricense_v3-1.pdf

Beláustegui, V. (2011). Las compras públicas sustentables en América Latina. Estado de avance y elementos clave para su desarrollo (Red Interamericana de Compras Gubernamentales, Documento de trabajo No. 3) Recuperado de http://www.oas. org/es/sap/dgpe/pub/compras2.pdf

Calderon, C. (2012). El desafio hacia el gobierno abierto en la hora de la igualdad. Santiago de Chile: Comisión Económica para América Latina y el Caribe -CEPAL.

Camargos M., \& Morais De, J. (2003). Compras governamentais: políticas e procedimentos na Organização Mundial de Comércio, União Européia, Nafta, Estados Unidos e Brasil (CEPAL, Serie Estudios y Perspectivas No. 1). Recu- 
perado de http://repositorio.cepal.org/ bitstream/handle/11362/4830/S036392_ fr.pdf? sequence $=1$

Cancelo. Á. (2015). Diez años de Contratación Pública Electrónica. Reflexiones y perspectivas de la puesta en práctica de la contratación electrónica desde Euskadi. Contratación administrativa práctica: revista de la contratación administrativa $y$ de los contratistas, 137, 144-153.

Cannolly, T., \& Begg, C. (2005). Sistemas de bases de datos. Madrid, España: Pearson.

Carbonell, L., \& Villagrá C. (2004). Introducción a las bases de datos Access 2003. Alicante, España: Universidad de Alicante.

Castells, M. (1996). The Information Age: Economy, Society, and Culture. Oxford, Inglaterra: Blackwell Publishers.

Comisión Europea. (2001). La gobernanza europea, un libro blanco. Bruselas: Diario oficial de las comisiones europeas.

Compromiso de Túnez de 2005. Construir la Sociedad de la Información: Un Desafío Global para el Nuevo Milenio (Segunda fase), noviembre de 2005.

Consejo Nacional de Política Económica y Social-[CONPES]. (21 de junio de 1995). Documento CONPES 2790. Recuperado de http://www.cioh.org.co/index.php/ component/docman/doc_download/233documento-conpes- 2790

Consejo Nacional de Política Económica y Social-[CONPES]. (09 de febrero de 2000). Documento CONPES 3072. Recuperado de http://www.mintic.gov.co/ portal/604/articles-3498_documento.pdf

Consejo Nacional de Política Económica y Social-[CONPES]. (31 de julio de 2002).
Documento CONPES 3186. Recuperado de http:/colombiacompra.gov.co/sites/ default/files/normativas/conpes3186.pdf

Consejo Nacional de Política Económica y Social-[CONPES]. (20 de octubre de 2003). Documento CONPES 3248. Recuperado de http://www.mintic.gov.co/portal/604/ articles-3499_documento.pdf

Consejo Nacional de Política Económica y Social-[CONPES]. (20 de octubre de 2003). Documento CONPES 3249. Recuperado de http://www.mintic.gov.co/portal/604/ articles-3500_documento.pdf

Contraloría General de la República. (s.f.). Informe ejecutivo contratación 2012-2013, metodología y resultados equipo 'A'. Recuperado de http://www.contraloria. gov.co/documents/10136/78918891/ Presentacion-Informe-Ejecutivo-PUBLICIDAD-7-0.pdf/929c39c9-a116-4769ab09-5cd3edbd680d

Date, C. (2001). An introduction to database systems (Trad. J. Vázquez, 7a ed.). Massachusetts, Estados Unidos: Addison Wesley Longman Inc.

Declaración de Florianópolis del 2000. Uso de las tecnologías de la Información y de las comunicaciones (TIC) para el desarrollo. CEPAL, junio de 2000. Santa Catarina, Brasil.

Declaración de Itacuruçá del 2000. El derecho al acceso universal a la información en el siglo XXI: los desafíos éticos, jurídicos y socioculturales de la Sociedad de Información para la América Latina y el Caribe. UNESCO, octubre de 2000. Estado de Río de Janeiro, Brasil.

Declaración de Río de Janeiro de 2001. Conferencia Regional Ministerial de América Latina y el Caribe Preparatoria para la 
Segunda Fase de la Cumbre Mundial de la Sociedad de la Información, junio de 2001. Estado de Río de Janeiro, Brasil.

Declaración de Bávaro de 2003. Conferencia Ministerial Regional de América Latina y el Caribe preparatoria para la Cumbre Mundial de la Sociedad de la Información, enero de 2003. Punta Cana, República Dominicana.

Declaración de Principios para el Nuevo Milenio de 2003. Construir la Sociedad de la Información: Un Desafío Global para el Nuevo Milenio (Primera fase de la Cumbre Mundial sobre la Sociedad de la Información), diciembre de 2003. Organización de las Naciones Unidas. Ginebra.

Declaración de Santiago de 2007. Carta Iberoamericana de Gobierno Electrónico. XVII Cumbre Iberoamericana de jefes de Estado y de Gobierno, noviembre de 2007. Santiago, Chile.

Declaración de México de 2010, Inter-American Telecommunication Commission, marzo de 2010. Recuperado en: ww.citel.oas.org

Declaración de La Granja 2010, Foro Ministerial de la Unión Europea con América Latina y el Caribe sobre la Sociedad de la Información, marzo de 2010. España.

Dirección ChileCompra (2013). Informe Mipe, proveedores micro y pequeños empresarios en ChileCompra. Recuperado de http://www.chilecompra.cl/phocadownload/ Noticias/informe $\% 20$ mipe $\% 20 \mathrm{web} . p d f$

Domínguez-Macaya, J. (2015). La insistencia de la UE en la Contratación Pública Electrónica y sus correspondientes decepciones. Contratación administrativa práctica: revista de la contratación administrativa y de los contratistas, 137, 7-19.
Fernández, C., \& Campos, C. (2004). Governo eletrônico e transformação da administração pública. En A. Chahin, et al. (Ed.), E-gov.br: a próxima revolução brasileira: eficiência, qualidade e democracia: o governo eletrônico no Brasil e no mundo (pp. 102-108). São Paulo: Prentice Hall.

Font, A., \& Ballestero, F. (2004). El despertar del e-Procurement en las Administraciones Públicas. Revista de economía, 813, 73-88.

González, A. (2009). La contratación pública electrónica. Cuadernos de Derecho Público, 37, 139-175.

Hernández J., Ramírez M., \& Ferri C. (2004). Introducción a la minería de datos, Madrid, España: Pearson.

Laguado, G. (2005). Política pública y el nuevo marco regulatorio de la contratación pública electrónica en Colombia. Universitas, 54(110), 147-190.

Laguado, R., \& Suárez, G. (2007). Manual de contratación pública electrónica para América Latina, Bases conceptuales, modelo legal, indicadores, parámetros de interoperabilidad (CEPAL, Colección Documentos de Proyectos). Recuperado de http://archivo.cepal.org/pdfs/2007/ S2007302.pdf

Martínez, R. (2015). La contratación pública electrónica: análisis y propuesta de transposición de las Directivas Comunitarias de 2014. Valencia: Tirant lo Blanch.

Medina, T. (2010). La apuesta europea por la contratación pública electrónica como buque insignia de la Administración electrónica, Revista Aranzadi de derecho y nuevas tecnologías, 22, 69-83.

Moreno, J. A. (2015). Análisis comparado de los recientes avances en contratación 
pública electrónica en América latina. Contratación administrativa práctica: revista de la contratación administrativa $y$ de los contratistas, 138, 12-14.

Naser, A. \& Concha G. (2011). El desafio hacia el gobierno abierto en la hora de la igualdad. (Comisión Económica para América Latina y el Caribe (CEPAL)., Documento de proyecto). Santiago de Chile. (pp. 11-26).

Nevado, M. (2010). Introducción a las Bases de Datos Relacionales. España: Visión libros.

Organización de las Naciones Unidas-[ONU], Comisión Interamericana de Telecomunicaciones-[Citel] \& Organización de los Estados Americanos-[OEA]. (2005). Libro azul: politicas de telecomunicaciones para las américas. Autor. Recuperado de https://www.citel.oas.org/en/SiteAssets/ About-Citel/Publications/BlueBook_e. pdf

Organización de los Estados Americanos[OEA]. (2002). Agenda de conectividad para las américas y plan de acción de Quito. Recuperado de http://programa. gobiernoenlinea.gov.co/apcaafiles/92e 2 edae878558af042aceeafd $1 \mathrm{fc} 4 \mathrm{~d} 8$ /quitoplan-of-action-sp_1.pdf

Patiño, R. (Ed.). (2009). Régimen de comercio exterior, temas de actualidad. México D.F: Porrúa; UNAM.

Punzón, J., \& Sánchez, F. (2005). El uso de las nuevas tecnologías en la Administración Pública: La contratación pública electrónica prevista en la Directiva 2004 / 18/ CE. Revista de derecho de las Telecomunicaciones e infraestructuras en red, 8(24), 63-96.

Reino de España. Ley 11 de 2007. De acceso electrónico de los ciudadanos a los
Servicios Públicos. Boletín Oficial del Estado No. 150. Jefatura del Estado, junio de 2007.

República de Chile. Ley 19.886 de 2003. Ley de Bases sobre Contratos Administrativos de Suministro y Prestación de Servicios. Diario Oficial de 30 de julio de 2003. Congreso de la República, julio de 2003.

República de Colombia. Decreto 2170 de 2002. Por el cual se reglamenta la ley 80 de 1993, se modifica el decreto 855 de 1994 y se dictan otras disposiciones en aplicación de la Ley 527 de 1999. Diario Oficial No. 44.952. Presidencia de la República, octubre de 2002.

República de Colombia. Decreto 3816 de 2003. Por el cual se crea la Comisión Intersectorial de Políticas y de Gestión de la Información para la Administración Pública. Diario Oficial 45.429. Presidencia de la República, diciembre de 2003.

República de Colombia. Decreto 3620 de 2004. Por el cual se crea la Comisión Intersectorial de Contratación Pública. Diario Oficial No. 45.727. Presidencia de la República, noviembre de 2004.

República de Colombia. Decreto 2434 del año 2006. Por el cual se reglamenta la Ley 80 de 1993, se modifica parcialmente el Decreto 2170 de 2002 y se dictan otras disposiciones. Diario Oficial No. 46.334. Presidencia de la República, julio de 2006.

República de Colombia. Decreto 1151 de 2008. Por el cual se establecen los lineamientos generales de la Estrategia de Gobierno en Línea de la República de Colombia, se reglamenta parcialmente la Ley 962 de 2005, y se dictan otras disposiciones. Diario Oficial No. 46.960. Presidencia de la República, abril de 2008. 
República de Colombia. Decreto 3043 de 2008. Por el cual se modifica y adiciona el Decreto 3816 de 2003. Diario Oficial No. 47.087. Presidencia de la República, agosto de 2008.

República de Colombia. Decreto 4170 de 2011. Por el cual se crea la Agencia Nacional de Contratación Pública -Colombia Compra Eficiente-, se determinan sus objetivos y estructura. Diario Oficial No. 48.242. Presidencia de la República, noviembre de 2011.

República de Colombia. Decreto 734 de 2012. Por el cual se reglamenta el Estatuto General de Contratación de la Administración Pública y se dictan otras disposiciones. Diario Oficial No. 48.400. Presidencia de la República, abril de 2012.

República de Colombia. Decreto 1510 de 2013. Por el cual se reglamenta el sistema de compras y contratación pública. Diario Oficial No. 48.854. Presidencia de la República, julio de 2013.

República de Colombia. Decreto ley 1250 de 1995. Por el cual se suprimen y reforman regulaciones, procedimientos o trámites innecesarios existentes en la Administración Pública. Diario Oficial No. 42.137. Presidencia de la República, diciembre de 1995.

República de Colombia. Ley 489 de 1998. Por la cual se dictan normas sobre la organización y funcionamiento de las entidades del orden nacional, se expiden las disposiciones, principios y reglas generales para el ejercicio de las atribuciones previstas en los numerales 15 y 16 del artículo 189 de la Constitución Política y se dictan otras disposiciones. Diario Oficial No. 43.464. Congreso de la República, diciembre de 1998 .

República de Colombia. Ley 527 de 1999. Por medio de la cual se define y reglamenta el acceso y uso de los mensajes de datos, del comercio electrónico y de las firmas digitales, y se establecen las entidades de certificación y se dictan otras disposiciones. Diario Oficial No. 43.673. Congreso de la República, agosto de 1999.

República de Colombia. Ley 790 de 2002. Por la cual se expiden disposiciones para adelantar el programa de renovación de la administración pública y se otorgan unas facultades Extraordinarias al Presidente de la República. Diario Oficial No. 45.046. Congreso de la República, diciembre de 2002.

República de Colombia. Ley 812 de 2003. Por la cual se aprueba el Plan Nacional de Desarrollo 2003-2006, hacia un Estado comunitario. Diario Oficial No. 45.231. Congreso de la República, junio de 2003.

República de Colombia. Ley 962 de 2005. Por la cual se dictan disposiciones sobre racionalización de trámites y procedimientos administrativos de los organismos y entidades del Estado y de los particulares que ejercen funciones públicas o prestan servicios públicos. Diario Oficial No. 46.023. Congreso de la República, septiembre de 2005.

República de Colombia. Ley 1150 de 2007. Por medio de la cual se introducen medidas para la eficiencia y la transparencia en la Ley 80 de 1993 y se dictan otras disposiciones generales sobre la contratación con Recursos Públicos. Diario Oficial No. 46.69. Congreso de la República, julio de 2007.

República de Colombia. Ley 1341 de 2009. Por la cual se definen principios y conceptos sobre la sociedad de la información y la organización de las Tecnologías de la Información y las Comunicaciones -TIC-, se crea la Agencia Nacional de Espectro y se dictan otras disposiciones. Diario Oficial No. 47.426. Congreso de la República, julio de 2009 . 
República de Colombia. Ley 1450 de 2011. Por la cual se expide el Plan Nacional de Desarrollo, 2010-2014. Diario Oficial No. 48.102. Congreso de la República, junio de 2011.

República Federativa del Brasil. Decreto 5.504 de 2005. Estabelece a exigência de utilização do pregão, preferencialmente na forma eletrônica, para entes públicos ou privados, nas contratações de bens e serviços comuns, realizadas em decorrência de transferências voluntárias de recursos públicos da União, decorrentes de convênios ou instrumentos congêneres, ou consórcios públicos. Diario Oficial del 5 de Agosto de 2005. Presidencia de la República, agosto de 2005.

República Federativa del Brasil. Ley 8.666 de 1993. Ley general de contratación pública. Boletín Oficial del 22 de junio de 1993. Congreso Nacional, junio de 1993.

República Federativa del Brasil. Ley 10.520 de 2002. Ley de comercio, establece el modo de hacer una oferta en la modalidad de subaste. Boletín Oficial del 18 de julio de 2002. Congreso Nacional, julio de 2002.

Rincón, E. (2003). Gobierno electrónico: Una aplicación al gasto público. Estudios Socio-Jurídicos, 5(2), 120-155.

Rincón, E. (2004). Últimos retos para el derecho privado: las nuevas tecnologías de la información. Revista de Estudios Socio-Jurídicos, 6(2), 430-500.

Rincón, E. (2006). Manual de Derecho de Comercio electrónico y de internet. Bogotá: Centro Editorial Rosarista.

Rincón E., \& Sánchez, C. (2004). Gobierno electrónico, en el contexto local de la ad- ministración colombiana. Revista Civilizar, 7, 1-26. Recuperado de http://www. usergioarboleda.edu.co/civilizar/archivo_publicacion_7.htm

Rivera, E. (2003). Nueva Economía, Gobierno Electrónico y Reforma del Estado, Chile a la luz de la Experiencia Internacional. Santiago de Chile: Flacso.

Romero, J. E. (2012). Derecho Internacional de las Contrataciones Públicas Electrónicas. San José de Costa Rica: Universidad de Costa Rica.

Romeu, J. R., Juárez, G., \& Pineda, C. (2014a). La Contratación Pública Electrónica como medio para hacer efectiva la Transparencia Administrativa. Revista de estudios locales. Cunal, 168, 52-74.

Romeu, J. R., Juárez, G., \& Pineda, C. (2014b). Efectos de la implantación de un sistema público de contratación por medios electrónicos y su incidencia en el panorama español: más allá de un cambio de formato. Trabajo presentado en congreso "Internet, Derecho y Política Una década de transformaciones" de la Universitat Oberta de Catalunya, Barcelona.

Saavedra, J. (2011). Reformas en los Mecanismos de Compras Públicas y las Mipymes. Buenos Aires: Universidad Nacional San Martin.

Santos De, M. (2011). La economía politica de las reformas de los sistemas de compras públicas en América Latina y el Caribe. Buenos Aires: Universidad Nacional San Martin.

Volosin, N. (Ed.). (2010). Promoviendo las compras públicas electrónicas para el desarrollo. Buenos Aires: Poder Ciudadano. 